\title{
PURWARUPA BEL PINTAR BERBASIS ARDUINO YUN
}

\author{
Hendra Kusumah ${ }^{1}$ \\ Ferry Sudarto ${ }^{2}$ \\ Dendy Jonas ${ }^{3}$ \\ ${ }^{123}$ Perguruan Tinggi Raharja \\ Email: hendra.kusumah@raharja.info ${ }^{1}$,ferrysudarto@raharja.info ${ }^{2}$,dendy.jonas@raharja.info ${ }^{3}$
}

\begin{abstract}
Computer technology has grow widely on helping humans in lot aspect. One of the computer field is embedded system which is now developed into a new field called Internet of Things. Internet of things or IOT has become a new trend in information technology because it function that could make humans job much more easier than before. One of those function include the capability to make an ordinary house into a smart house that connected to internet. A smart house definition can be divided into a few parts and one of it is a bell which could tell that somebody is in the front of the house and it also has the ability to send the picture of that person to owner's email when there are nobody at home.
\end{abstract}

Keyword: Embedded System, Internet of Things, Smart House

\begin{abstract}
ABSTRAK
Teknologi komputerisasi telah berkembang dalam membantu berbagai aspek kehidupan manusia. Salah satunya bidang komputerisasi itu adalah embedded system yang sekarang telah berkembang menjadi sebuah bidang baru dalam dunia komputerisasi yaitu Internet of Things. Internet of Things atau IOT menjadi sebuah konsep hangat dan akan menjadi trend baru dalam bidang teknologi informasi karena fungsinya yang mampu membuat pekerjaan manusia jauh lebih mudah dari sebelumnya. Salah satu fungsi tersebut adalah kemampuannya untuk menjadikan sebuah rumah biasa menjadi sebuah rumah yang pintar dan terkoneksi dengan internet. Untuk menjadikan sebuah rumah dikatakan sebagai rumah pintar dapat diuraikan menjadi beberapa bagian, dan salah satu bagian itu adalah sebuah bel rumah yang berfungsi tidak hanya berbunyi saja untuk memberitahu ada orang di depan rumah, namun bel tersebut juga mampu untuk mengirimkan notifikasi melalui internet dan mengirimkan gambar orang tersebut ketika tidak ada orang di rumah.
\end{abstract}

Kata Kunci: Embedded System, Internet of Things, Rumah Pintar

\section{PENDAHULUAN}

Teknologi komputerisasi telah berkembang dalam membantu berbagai aspek kehidupan manusia. Salah satunya bidang komputerisasi itu adalah embedded system yang sekarang telah berkembang menjadi sebuah bidang baru dalam dunia komputerisasi yaitu Internet of Things. Teknologi Internet of Things atau IOT sedang menjadi perbincangan yang hangat di dunia Teknologi Informasi. Vendorvendor elektronik dan komputer ternama 
seperti Samsung, LG, Intel, Microsoft, dan sebagainya berlomba-lomba membuat sebuah platform IOT mereka sendiri.

Platform atau framework IOT tersebut dibuat dengan satu tujuan yaitu untuk menghubungkan semua hal yang biasa kita temui atau pakai sehari ke dalam dunia Internet yang luas. Karena dengan terhubung benda-benda tersebut, sudah pasti akan lebih meringankan pekerjaan yang biasa kita lakukan dalam bidang apapun. Pemakaian IOT inipun sudah diaplikasikan dalam berbagai bidang seperti industri, transportasi, pertanian, perumahan, dll.

Dengan berbagai kemudahan yang bisa dilakukan oleh IOT menciptakan banyak potensi alat baru yang bisa dibuat. Berdasarkan hal tersebut tercetus sebuah alat dalam bidang perumahan yang mampu membantu para pemilik rumah yang semua anggota keluarganya mempunyai kesibukan dan tidak mempunyai waktu banyak di rumah atau rumah yang sedang tidak di huni karena semua anggotanya sedang berlibur untuk waktu yang cukup lama.

Permasalahan tersebut menjadi dasar sebuah ide untuk membuat sebuah alat yang mengusung konsep IOT yaitu Bel Pintar yang mampu memberi notifikasi kepada pemilik rumah kapanpun dan dimanapun jika ada orang yang mampir atau berada di depan rumah.

\section{PERMASALAHAN}

Masalah adalah kesenjangan (discrepancy) antara apa yang seharusnya (harapan) dengan apa yang ada dalam kenyataan sekarang. Penelitian diharapkan mampu mengantisipasi kesenjangan-kesenjangan tersebut. Masalah yang perlu dijawab melalui penelitian cukup banyak dan bervariasi misalnya masalah dalam bidang teknologi.

Rumusan masalah dalam penelitian ini adalah bagaimana cara untuk membuat sebuah alat yang mampu memberitahu pemilik rumah bahwa ada seseorang yang berada di rumah pada saat rumah tersebut sedang kosong. Orang yang datang tersebut sudah pasti mempunyai kepentingan tertentu terhadap pemilik rumah dan mungkin orang tersebut juga mempunyai waktu yang terbatas untuk berkunjung ke rumah tersebut. Berdasarkan masalah tersebut maka tujuan yang ingin dihasilkan adalah informasi tentang orang yang sedang berada di depan rumah dan menanyakan apa maksud dari kedatangan orang tersebut ke rumah. Alat yang akan dibuat menggunakan beberapa komponen sederhana yang beberapa diantaranya cukup mudah didapat. Komponenkomponen tersebut meliputi Arduino Yun, Push Button, USB Webcam, dan Adaptor $5 \mathrm{~V}$.

Arduino Yun adalah salah satu Platform mikrokontroler yang dikeluarkan oleh perusahaan bernama Arduino yang berasal dari Italia. Keunggulan dan hal yang membuat Arduino Yun ini berbeda dari produk Arduino lainnya adalah kemampuannya untuk terkoneksi dengan wifi tanpa komponen tambahan dan Arduino Yun juga sudah mempunyai sistem operasi Linux yang sangat ringan berbasis OpenWRT bernama Linino. Dengan kemampuan inilah Arduino Yun menjadi lebih mudah untuk dikonfigurasi dan dibuat menjadi sebuah alat baru yang mengususng konsep IOT.

\section{LANDASAN TEORI}

Arduino adalah kit elektronik atau papan rangkaian elektronik open source yang di dalamnya terdapat komponen utama yaitu sebuah chip mikrokontroler dengan jenis AVR dari perusahaan Atmel. Arduino 
dikatakan sebagai sebuah platform dari physical computing yang bersifat open source. Pertama-tama perlu dipahami bahwa kata "platform" di sini adalah sebuah pilihan kata yang tepat. Arduino tidak hanya sekedar sebuah alat pengembangan, tetapi kombinasi dari hardware, bahasa pemrograman dan Integrated Development Environment (IDE) yang canggih. IDE adalah sebuah software yang sangat berperan untuk menulis program, meng-compile menjadi kode biner dan meng-upload ke dalammemory microcontroller.

Menurut Feri Djuandi (2011:8), "Komponen utama didalam papan Arduino adalah sebuah mikrokontroler 8 bit dengan merk ATmega yang dibuat oleh Atmel Corporation.Berbagai papan Arduino menggunakan tipe ATmega yang berbedabeda tergantung dari spesifikasinya., sebagai contoh Arduino Uno menggunakan ATmega328 sedangkan Arduino Mega 2560 yang lebih canggih menggunakan ATmega2560."

Menurut Dwi Agus Diartono (2009:70), "Bluetooth adalah sebuah teknologi komunikasiwireless (tanpa kabel) yang beroperasi dalam pita frekuensi $2,4 \mathrm{GHz}$ unlicensed ISMIndustrial, Scientific and Medical) dengan menggunakan sebuah frequency hopping transceiver yang mampu menyediakan layanan komunikasi data dan suara secara real-time antara hosthost Bluetooth dengan jangkauan layanan yang terbatas.

Menurut forbes.com Internet Of Things adalah sebuah jaringan besar yang terdiri dari alat-alat atau benda-benda yang terkoneksi satu sama lain. Koneksi tersebut bisa terdiri dari satu benda ke benda lainnya dan benda ke manusia.

\section{LITERATURE REVIEW}

1. Penelitian yang dilakukan oleh Nurdansyah dari STMIK Raharja yang berjudul "HOME APPLIANCES
CONTROLING WITH MOBILE DEVICE BASED ON ANDROID OS" pada tahun 2013. Penelitian ini membahas tentang pengendalian peralatan rumah menggunakan Smratphone Android menggunakan media jaringan wireless.

2. Penelitian yang dilakukan oleh Muhammad Bintar dari Perguruan Tinggi Raharja yang berjudul "SISTEM PENGONTROLAN LAMPU MENGGUNAKAN INPUT SUARA BERBASIS ARDUINO" pada tahun 2013. Penelitian ini menjelaskan tentang pengendalian lampu menggunakan arduino dan android.

3. Penelitian yang dilakukan oleh Reza Handaru Winasis (2014) yang berjudul "Pemanfaatan Sensor Accelorometer pada Smartphone Android Sebagai Kendali Pagar Rumah Melalui Bluetooth". Penelitian ini mambahas tentang mengendalikan pintu pagar rumah, yang dapat dilakukan dengan memanfaatkan Sensor Accelerometer. Dengan menggunakan aplikasi Android Sensor Accelerometer mengirimkan String tertentu kepada mikrokontroller ATmega 8 melalui komunikasi Bluetooth HC-05 untuk membuka pintu pagar rumah.

4. Penelitian Supriyadi dari STMIK RAHARJA Tangerang yang berjudul "Pemanfaatan Teknologi Bluetooth Untuk Indikator Posisi Suatu Benda" tahun 2013. Pada penelitian ini bertujuan memanfaatkan media bluetooth untuk membantu mencari posisi suatu benda.

5. Penelitian yang dilakukan oleh Teguh Arif Gustaman dari Institut Teknologi Sepuluh November Surabaya yang berjudul " PENGENDALI PINTU GERBANG MENGGUNAKAN BLUETOOTH BERBASIS MIKROKONTROLLER ATMEGA 8" pada tahun 2010. Penelitian ini menjelaskan tentang pengiriman sebuah kode karakter melalui Bluetooth. 
6. Penelitian yang dilakukan oleh Herman Putra Aritonang dari STMIK LOGIKA Medan yang berjudul "MEMANFAATKAN QR CODE \& SMARTPHONE ANDROID SEBAGAI ALAT ABSENSI PEGAWAI". Penelitian ini menjelaskan tentang Qr Code sebagai identifikasi absen.

7. Penelitian yang dilakukan oleh Satriyo Budi Santoso dari Perguruan Tinggi Raharja yang berjudul "Perancangan Miniatur Palang Perlintasan Kereta API MenggunakanInfrared dan Mikrokontroller AT89S51 Pada PT.KAI pada tahun 2013.

\section{PEMECAHAN MASALAH}

\section{HARDWARE}

Untuk mencapai pemecahan masalah yang ada, dibuat sebuah purwarupa alat yang akan memakai Arduino Yun sebagai otak dari keseluruhan proses yang ada. Arduino Yun tersebut ditambahkan beberapa komponen tambahan seperti push button, USB webcam, breadboard, dan beberapa kabel jumper.

Sistem kerja alat berdasarkan blok diagram berikut

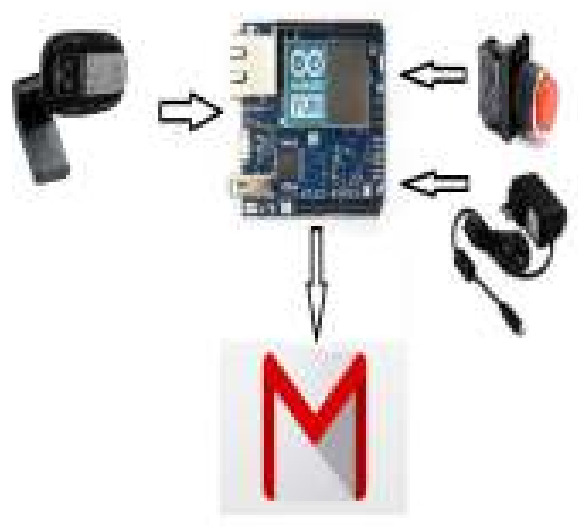

Gambar 1. Blok Diagram

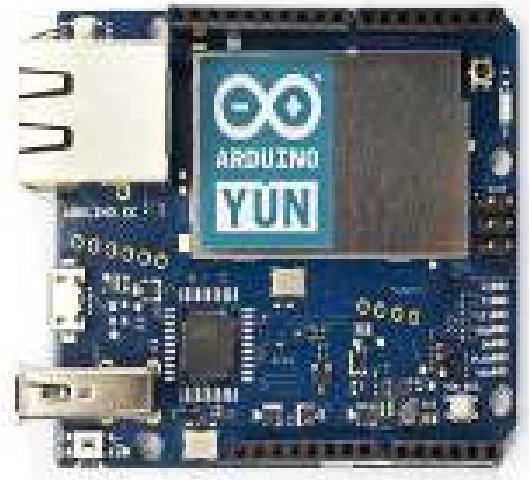

Gambar 2. Arduino Yun

Arduino Yun

Sebagai pusat pemrosesan semua data pada sistem. Arduino Yun mendapatkan aksi ketika tombol atau push button ditekan yang akan mengaktifkan kamera untuk mengambil gambar orang yang menekan tombol tersebut. Gambar tersebut selanjutnya dikirim langsung ke email pemilik rumah.

Pada Arduino Yun ini telah di upload arduino sketch yang dibuat sesuai dengan kebutuhan sistem. Selain arduino sketch, pada sisi sistem operasi linino telah diaktifkan sebuah script bahasa pemrogram python yang berfungsi untuk mengirimkan gambar ke email pemilik rumah.

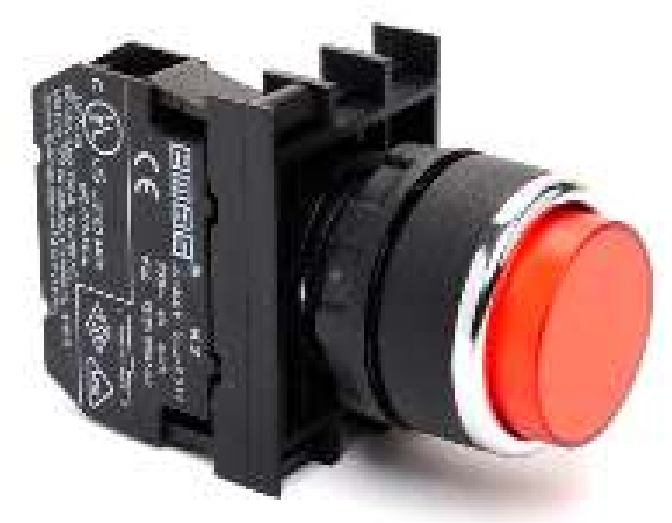




\section{Gambar 3. Push Button}

Push Button

Sebagai pemicu dari keseluruhan sistem, push button ini ditekan oleh orang yang berada di depan rumah dan berfungsi sama seperti sebuah bel rumah biasa. Hanya saja bel ini tidak mengeluarkan suara namun bel ini mengirimkan data ke pemilik rumah melalui email.

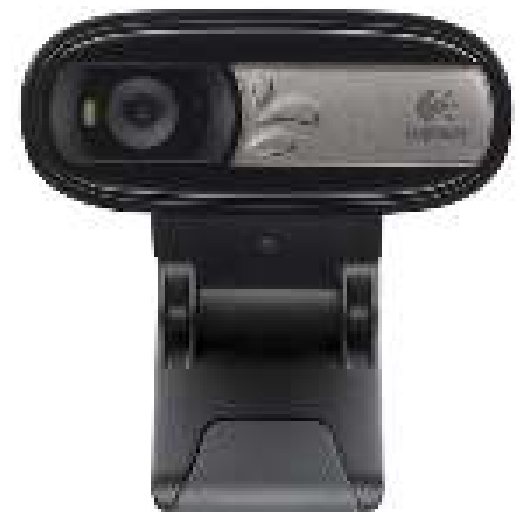

Gambar 4. Usb Webcam

USB webcam

Webcam yang dipakai adalah Logitech C170 yang mampu dibaca langsung oleh arduino yun. Webcam berfungsi mengambil gambar ketika tombol bel ditekan, Gambar tersebut akan tersimpan di memori Arduino Yun untuk selanjutnya dikirim ke email melalui script python yang sudah dibuat.

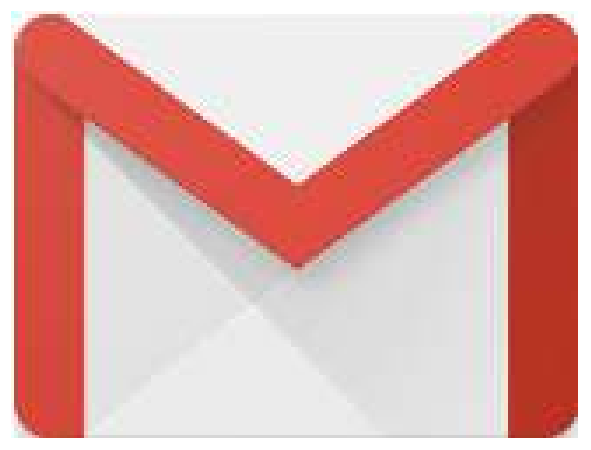

Gambar 5. Gmail
Gmail

Gmail ini terdapat di hampir semua device yang dimiliki oleh semua orang. Pemilik rumah memasang aplikasi Gmail pada Smartphone lalu membuat akun gmail dan melakukan login pada aplikasi gmail tersebut. Akun gmail tersebut telah ditanamkan pada script python yang ada pada arduino yun. Jika Script pada arduino yun aktif, maka gmail ini akan menerima data gambar yang telah dikirim oleh arduino yun tersebut.

\section{SOFTWARE}

Untuk menjalankan sistem purwarupa bel pintar ini dibutuhkan dua buah script yang berbeda bahasa. Script yang pertama menggunakan Arduino IDE yang menggunakan bahasa pemrograman berbasis bahasa C. Sedangkan script yang satu lagi menggunakan bahasa pemrograman python yang sudah tertanam pada arduino Yun.

Arduino Sketch

\#include $<$ Bridge.h $>$

\#include $<$ Process.h $>$

\section{// Picture process}

Process picture;

\section{// Filename}

//String filename;

//String path = "/mnt/sda1/"; 
// constants won't change. They're used

here to

// set pin numbers:

const int buttonPin $=4 ; \quad / /$ the number of the pushbutton pin

const int ledPin $=13 ; \quad / /$ the number of the LED pin

// variables will change:
int buttonState $=0 ; \quad$ // variable for
reading the pushbutton status
int DelaySeconds $=0 ;$
void setup ()\{
Bridge.begin( $) ;$

\section{// initialize the LED pin as an output:}

pinMode(ledPin, OUTPUT);

// initialize the pushbutton pin as an input:

pinMode(buttonPin, INPUT);

\}

$\operatorname{void} \operatorname{loop}()\{$

// read the state of the pushbutton value:

buttonState $=$ digitalRead (buttonPin);

// check if the pushbutton is pressed.

// if it is, the buttonState is HIGH:

if (buttonState $==\mathrm{HIGH})\{$

// turn LED on:
digitalWrite(ledPin, HIGH);

picture.runShellCommand("fswebcam -r 640x480 -S 20 /mnt/sda1/test.png");

while(picture.running());

// We don't want to take constant pictures so we force a delay each time we take one

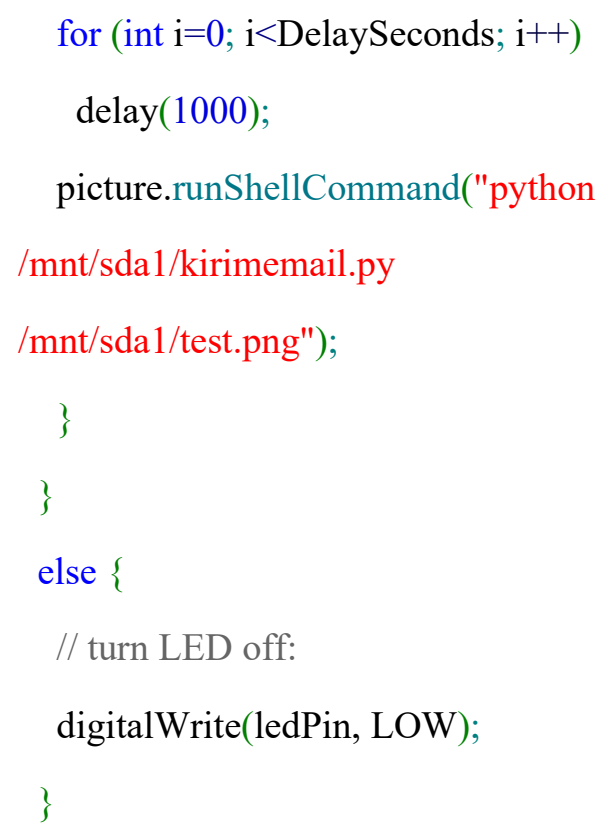

Script ini berfungsi untuk menangkap status dari pin 4 yang sudah tersambung dengan push button. Jika push button ditekan akan mengaktifkan pin 4 kedalam status HIGH yang kemudian akan mengaktifkan aplikasi fswebcam yang sudah terpasang pada Linino untuk mengambil gambar dan menyimpannya. Setelah gambar diambil bagian kode berikutnya akan mengaktifkan sebuah script python untuk mengirimkan gambar. 
Python Script

import smtplib, os, sys

from email.MIMEMultipart import

MIMEMultipart

from email.MIMEBase import

MIMEBase

from email.MIMEText import MIMEText

from email.Utils import COMMASPACE,

formatdate

from email import Encoders

\#From address, to address, subject and message body

from_address='xxxx@email.xxx'

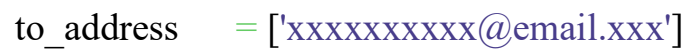

email_subject = 'Ada Seseorang Di Depan

Rumah'

email_body = 'Ada Orang yang

memencet bel rumah. Berikut adalah foto

dari orang tersebut'

\# Credentials (if needed)

username = 'xxxx@email.xxx'

password = 'password'

\# The actual mail send

server $=$ 'smtp.gmail.com:587' def send mail(send from, send to, subject, text, files=[], server="localhost"):

assert type(send_to $)=$ list

$\operatorname{msg}=$ MIMEMultipart()

$\operatorname{msg}[$ 'From'] $=$ send_from

$\operatorname{msg}\left[{ }^{\prime T o '}\right]$

COMMASPACE.join(send_to)

msg['Date']

formatdate (localtime $=$ True $)$

$\operatorname{msg}[$ 'Subject'] $=$ subject

msg.attach( MIMEText(text) )

for $\mathrm{f}$ in files:

part = MIMEBase('application',

"octet-stream")

part.set_payload( open(f,"rb").read() )

Encoders.encode_base64(part)

part.add_header('Content-Disposition',

'attachment; $\quad$ filename="\%s"' $\%$

os.path.basename(f))

msg.attach(part)

smtp $=$ smtplib.SMTP(server $)$

smtp.starttls()

smtp.login(username,password) 
smtp.sendmail(send_from, send_to,

msg.as_string())

smtp.close()

send_mail(from_address, to_address,

email_subject, email_body, [sys.argv[1]],

server) \#the first command line argument

will be used as the image file name

Script python ini aktif setelah gambar pada webcam telah selesai diambil. Pada script ini digunakan beberapa library yang sudah ada di dalam pustaka python. Alamat email yang dipakai untuk purwarupa alat ini adalah email yang berbasis gmail namun alamat email yang lain pun bisa dipakai. Pesan yang akan dikirim ke email pun bisa dirubah sesuai dengan keinginan atau kebutuhan pemilik rumah.

\section{IMPLEMENTASI}

Alat Purwarupa ini telah dicoba dengan menggunakan koneksi internet dengan bandwidth sebesar 2 mbps. Alat ini sebelumnya telah dikonfigurasi untuk terkoneksi ke internet melalui router yang telah terpasang di rumah. Setelah dilakukan percobaan dan penyesuian kode, alat ini berhasil untuk berfungsi sesuai dengan yang diharapkan.

Berikut adalah salah satu contoh gambar yang telah dikirim oleh alat tersebut.

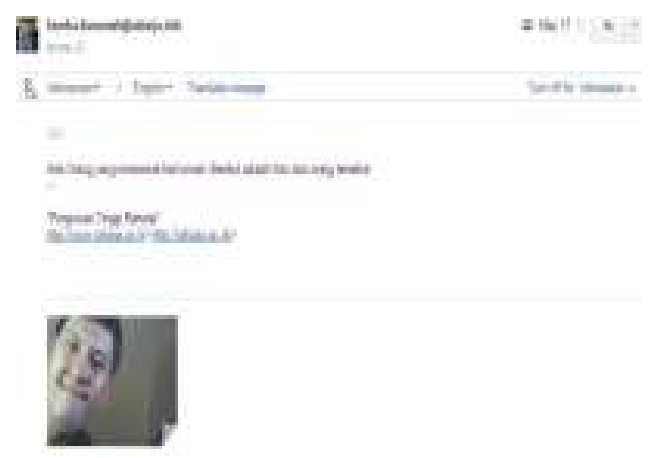

Gambar 6. Gambar Diterima

Alat yang dibuat masih sangat sederhana karena masih dalam tahap purwarupa, komponen tambahan masih disambungkan dengan menggunakan kabel jumper.

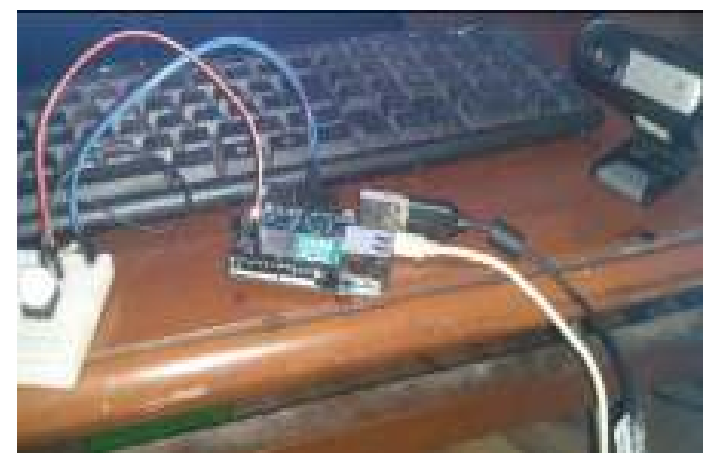

Gambar 7. Purwarupa Alat

\section{KESIMPULAN}

Dengan pembuatan alat purwarupa bel pintar ini dapat menangggulangi dan membantu salah satu masalah yang ada pada saat rumah sedang kosong. Alat purwarupa ini masih mempunyai banyak potensi untuk dikembangkan lebih jauh lagi. Namun untuk saat ini manfaat yang didapatkan dari alat ini masih tergolong cukup. Karena alat ini sudah mampu untuk memberitahu pemilik rumah jika ada orang yang sedang mampir atau datang ke rumah pada saat tidak ada orang yang berada dirumah. Alat ini pun nantinya bisa dikembangkan menjadi sistem keamanan yang lebih pintar dengan penambahan beberapa komponen dan fungsi pada softwarenya. 


\section{DAFTAR PUSTAKA}

1. Banzi, Massimo. "Getting Started With Arduino", ISBN: 978-0-59615917-7

2. Simarmata, Janner.2010. "RekayasaPerangkatLunak". Yogyakarta: Andi Offset

3. Sulindawati dan Muhammad Fathoni.2010. "Pengantar Analisa Sistem Jurnal SAINTIKOM Vol.9,No.2 Agustus 2010:2-19.

4. http://arduino.cc/en/Main/Arduino BoardUno, diakses pada tanggal 11 Juni 2015

5. http://www.forbes.com/sites/jacob morgan/2014/05/13/simple-

explanation-internet-things-thatanyone-can-understand/ diakses pada tanggal 11 Juni 2015 